\title{
Controlled Release of DEET Loaded on Fibrous Mats from Electrospun PMDA/Cyclodextrin Polymer
}

\author{
Claudio Cecone ${ }^{1}$, Fabrizio Caldera ${ }^{1}$, Francesco Trotta ${ }^{1}$, Pierangiola Bracco ${ }^{1, *(D)}$ \\ and Marco Zanetti ${ }^{1,2, *}$ \\ 1 Department of Chemistry and NIS Centre, University of Turin, Via P. Giuria 7, 10125 Torino, Italy; \\ claudio.cecone@unito.it (C.C.); fabrizio.caldera@unito.it (F.C.); francesco.trotta@unito.it (F.T.) \\ 2 ICxT Centre, University of Turin, Lungo Dora Siena 100, 10153 Torino, Italy \\ * Correspondence: pierangiola.bracco@unito.it (P.B.); marco.zanetti@unito.it (M.Z.); \\ Tel.: +39-011-6707547 (P.B. \& M.Z.)
}

Academic Editor: Bernard Martel

Received: 11 June 2018; Accepted: 9 July 2018; Published: 11 July 2018

\begin{abstract}
Electrospun beta-cyclodextrin $(\beta C D)$-based polymers can combine a high surface-tovolume ratio and a high loading/controlled-release-system potential. In this work, pyromellitic dianhydride (PMDA)/ $\beta C D$-based nanosponge microfibers were used to study the capability to host a common insect repellent ( $N, N$-diethyl-3-toluamide (DEET)) and to monitor its release over time. Fibrous samples characterized by an average fibrous diameter of $2.8 \pm 0.8 \mu \mathrm{m}$ were obtained and subsequently loaded with DEET, starting from a $10 \mathrm{~g} / \mathrm{L}$ diethyl ether (DEET) solution. The loading capacity of the system was assessed via HPLC/UV-Vis analysis and resulted in $130 \mathrm{mg} / \mathrm{g}$. The releasing behavior was followed by leaving fibrous DEET-loaded nanosponge samples in air at room temperature for a period of between $24 \mathrm{~h}$ and 2 weeks. The releasing rate and the amount were calculated by thermogravimetric analysis (TGA), and the release of the repellent was found to last for over 2 weeks. Eventually, both the chemical composition and sample morphology were proven to play a key role for the high sample loading capacity, determining the microfibers' capability to be applied as an effective controlled-release system.
\end{abstract}

Keywords: N,N-diethyl-3-toluamide (DEET); insect repellent; beta-cyclodextrin-based polymer; fibrous nanosponge; controlled-release system

\section{Introduction}

Intensification of human travel and transcontinental commerce are the main causes related to the spreading of most of the emerging infectious diseases. This threat comes from zoonotic viruses transmitted to humans by hematophagous insects such as mosquitoes, sandflies, midges, and ticks, and the diseases are thus designated as arthropod-borne viruses (arboviruses) [1]. Arboviral infections can range from asymptomatic to fulminant fatal diseases and can be caused by at least 135 arboviruses. In most cases, the occurrence of a major outbreak is due to the introduction of viruses in new geographic areas where the hosts are susceptible and able to sustain infection [2]. Lyme disease; Heartland virus disease; borreliosis; and 346 rickettsiosis (tick-borne), dengue, and chikungunya (mosquito-borne) diseases are some of the most recent diseases described in the United States and Europe. With few exceptions, these infectious diseases cannot be prevented by vaccinations [3]. In order to prevent insects landing and biting, effective preventive measures are window screens and insect-repellent formulations in buildings and open environments. Repellents are natural or synthetic chemical substances applied to clothing or skin; the main vehicles for these formulations are sprays, lotions, and gels. Among the synthetic repellents, $N, N$-diethyl-3-toluamide (DEET), ethyl 
butylacetylaminopropionate (EB), and 1-(1-methylpropoxycarbonyl)-2-(2-hydroxyethyl) (picaridin or icaridin) are the most widely used [4]. Despite that its discovery dates back to 1946, DEET remains the most popular and successful product. It is a yellowish, oily, volatile liquid (at room temperature) that is characterized by an unpleasant odor and is moderately soluble in petroleum ether, insoluble in water, and very soluble in alcohol. DEET is incorporated into topical formulation from $7 \mathrm{wt} \%$ (short repellent action, up to $2 \mathrm{~h}$ ) to $30 \mathrm{wt} \%$ (long period action, up to $6 \mathrm{~h}$ ) [5]. With proper application, the safety record of DEET has proven to be excellent, with most of the toxicity cases confined to children after overapplication or ingestion [3]. However, at high concentrations and after prolonged exposure, adverse effects have been reported, caused by the presence of DEET in the bloodstream. As a result of its lipophilic feature, it can be absorbed by the skin and pass through the cutaneous barrier, reaching deeper layers and blood vessels [6]. Skin rash, seizures, encephalopathy, and central nervous system toxicity have been reported [7-9]. Moreover, DEET has also been found to damage synthetic fabrics, leather, plastics, and painted surfaces [3,7]. One effective strategy to avoid DEET-based-formulation drawbacks could be loading the molecule into a proper absorbent system, such as a high-surface-to-volume-ratio matrix. In this way, the contact between the repellent and both skin and fabrics would be minimized. A fibrous morphology would increase the surface-to-volume ratio, and the choice of suitable materials would enhance the repellent loading capacity.

Beta-cyclodextrins $(\beta C D s)$, cyclic oligosaccharides obtained enzymatically from starch, are composed of seven $\alpha-(1,4)$-linked glucopyranose units, arranged surrounding a slightly lipophilic cavity in a peculiar truncated-cone-shaped structure. Because of the presence of a lipophilic domain, $\beta C D$ s can accommodate guest molecules through the formation of inclusion complexes [10]. Additionally, because of the presence of a high number of hydroxyl functionalities, $\beta C D$ s can be used as building blocks for several polymer synthesis techniques. Several classes of di-, tri- or tetra-functional molecules, such as carbonyldiimidazole, pyromellitic dianhydride (PMDA), hexamethylene diisocyanate, and citric acid, have been reported as $\beta C D$ linking molecules [11]. By choosing proper synthetic conditions, both water-soluble (hyper-branched) and water-insoluble (cross-linked or nanosponge) polymers have been successfully obtained [12]. As a result of their tuneable syntheses, these types of polymers are adopted in several applications, such as for drug carriers, gas traps, fillers, cosmetic photo-stabilizers, metal cation absorbers, and fire-retardant agents $[13,14]$.

The DEET loading capacity and controlled release of a $\beta C D$-grafted cotton fabric have been previously reported [15]. However, the system described displayed weak repellency effects against mosquitoes. This behavior was related to a slow DEET volatilization from the matrix, likely as a result of a small loaded quantity and a strong interaction between the repellent and fabric. Unlike that reported for a $\beta C D$-grafted fabric, a $\beta C D$-based polymer, synthesized using $\beta C D$ as the polymer building block, would be characterized by a higher number of hosting sites. Thus, a higher DEET loading capacity and higher releasing rates would be expected. Moreover, this kind of DEET-loaded matrix may result in a prolonged and controlled-release system and may eventually be helpful to minimize toxicity, health problems, and fabric-damage issues.

Electrospinning is a powerful technique that allows microfiber and nanofiber deposition from a material dissolved in a solvent through an electrically forced fluid jet [16]. Filtration, tissue engineering, biosensors, drug delivery, wound dressings, and enzyme immobilization are just a few of the applications covered by electrospun fibers [17]. As a result of an electric field applied between a nozzle and a collector, stretching (towards the collector) of a polymeric solution (or melt) that flows out of the nozzle is induced. A volumetric pump keeps a constant flow while the field is managed by an electric field generator. Micrometric dimensions and a high surface-to-volume ratio of the produced fibrous mats, as well as simplicity, versatility, and cost-efficiency, are the main features of this technique [18].

Obtaining fibers starting from a water-soluble $\beta C D$-based polymer would offer the possibility to obtain a high-surface-to-volume-ratio product, capable to entrap guest molecules and release them over the time. We recently demonstrated the possibility to use a simple thermal treatment to convert 
$\beta C D$-based fibers, electrospun from a water solution, into a water- and organic-solvent-insoluble mat [19].

In the present study, we investigated the capability of such fibrous $\beta C D$-based nanosponges to host chemicals, in this case, a common insect repellent (DEET), and to gradually release them over time. The fibrous nanosponges were obtained by thermally treating an electrospun mat, processed starting from a water-soluble $\beta C D /$ PMDA polymer.

\section{Experimental Section}

\subsection{Materials}

Dimethyl sulfoxide (DMSO), triethylamine, PMDA, ethyl acetate, DEET, and ethyl ether were purchased from Sigma-Aldrich (Darmstadt, Germany) and were used as received. $\beta C D$ was provided by Roquette Italia (Cassano Spinola, Italy) and was dried in an oven at $100{ }^{\circ} \mathrm{C}$ up to a constant weight before use. The cotton fabric used was a lint-free 100\% medium-weight cotton twill (5 oz) from the Agilent GC-MS (Santa Clara, CA, USA) cleaning kit; as was the cotton swab.

\subsection{Polymer Synthesis}

The polymer synthesis was performed following the procedure described in the work of Trotta et al. (2014) [20]. Briefly, $6 \mathrm{~mL}$ of DMSO was used to dissolve $0.977 \mathrm{~g}(0.86 \mathrm{mmol})$ of anhydrous $\beta C D$. Subsequently, $1 \mathrm{~mL}$ ( $7.17 \mathrm{mmol})$ of TEA was added as a catalyst, followed by $2.254 \mathrm{~g}(10.33 \mathrm{mmol})$ of PMDA introduced under vigorous stirring at room temperature. This step was related to a solution viscosity increase. After $24 \mathrm{~h}$, an excess of ethyl acetate was used to precipitate and wash the product from the reactive media, which was recovered by vacuum filtration. Afterwards, the dry product was solubilized in deionized water, freeze-dried, and finally stored in a desiccator. Considering the weight of the freeze-dried polymer with respect to the theoretical weight, equal to the sum of $\beta C D$ and PMDA, the yield result was approximately $90 \%$.

\subsection{Polymer Processing and Curing}

The polymer processing and its thermal treatment were performed according to the work of Cecone et al. (2018) [19]. In short, a $59 \mathrm{wt} \%$ distilled water/polymer solution was chosen as the optimum fiber-forming concentration. The electrospinning was performed by setting the working distance to $15 \mathrm{~cm}$, the field strength to $30 \mathrm{kV}$, and the flow to $1.2 \mathrm{~mL} / \mathrm{h}$. The thermal treatment was performed at $180{ }^{\circ} \mathrm{C}$ under nitrogen flow with a $10{ }^{\circ} \mathrm{C} / \mathrm{min}$ heating rate, followed by $10 \mathrm{~min}$ isotherm.

\subsection{Fibrous-Nanosponge DEET Loading and Extraction Procedures}

DEET loading was performed using $5 \mathrm{~mL}$ of a $10 \mathrm{~g} / \mathrm{L}$ diethyl ether (DEET) solution per loading. Each substrate $(100 \mathrm{mg})$ was left in the solution for $24 \mathrm{~h}$ and was then recovered, dried, and stored. Before loading, each substrate was dried in an oven at $70^{\circ} \mathrm{C}$.

DEET extraction from the loaded polymer was performed using a methanol/water $(57 / 43 \mathrm{vol} / \mathrm{vol})$ mixture. Eight extractions were set, starting from $10 \mathrm{mg}$ of loaded polymer. Except for the last extraction, which lasted $24 \mathrm{~h}$ without additional treatments, each extraction lasted 30 min under sonication at room temperature, using $1 \mathrm{~mL}$ of extracting mixture each. All the extracted fractions were separated from the solid by centrifugation, recovered, and stored in a freezer. After each extraction, fresh mixture was used to start the next.

\subsection{Cotton Samples' Loading Procedure}

In order to compare the loading capacity of the $\beta C D$ polymer with that of conventional natural fabrics, two cotton samples, in the form of a swab and fabric, were also loaded with DEET. The loading step was performed following the procedure described above for the fibrous nanosponges. 


\subsection{Nanosponge-Powder Loading Procedure}

In order to investigate the effect of the fibrous morphology on the loading capacity of the system, the same $\beta C D$-based polymer, cured without being processed into fibers (polymer powder), was also loaded with DEET. The loading step was performed following the procedure described above for the fibrous nanosponges.

\subsection{Fibrous-Nanosponge DEET Release Study Setup}

In order to evaluate the DEET release rate from the matrix, five samples of $10 \mathrm{mg}$ each were prepared from the spun DEET-loaded mat. These samples were then left in air and at room temperature for $24 \mathrm{~h}, 48 \mathrm{~h}, 72 \mathrm{~h}, 1$ week, and 2 weeks, and a thermogravimetric analysis (TGA) was performed at each time interval.

\subsection{Scanning Electron Microscopy Analysis}

The morphological features of the fibers were checked using scanning electron microscopy (SEM). The images were acquired with a Leica Stereoscan 410 Oxford Instrument (Abingdon, UK), using secondary electrons and a $10 \mathrm{kV}$ accelerating voltage.

\subsection{Thermogravimetric Analysis Measurements}

TGA was carried out using a TA Instruments Q500 TGA (New Castle, DE, USA), from 50 to $400{ }^{\circ} \mathrm{C}$, under nitrogen flow, and with a heating rate of $10^{\circ} \mathrm{C} / \mathrm{min}$.

\subsection{HPLC Measurements}

A Perkin-Helmer (Waltham, MA, USA) Flexar liquid chromatograph (HPLC) was used to check the total amount of DEET released by the loaded polymer after the extractions.

A 1 to 100 ppm calibration curve was constructed before the sample analysis. A C-18 column was installed for the measure, and a $1 \mathrm{~mL} / \mathrm{min}$ methanol/water $(57 / 43 \mathrm{vol} / \mathrm{vol})$ flow was used as the mobile phase. The released DEET, as well as the DEET used for the calibration, were measured with a UV-Vis detector at $220 \mathrm{~nm}$. The duration of a single run was $15 \mathrm{~min}$, with a DEET retention time of $11 \mathrm{~min}$.

\section{Results and Discussion}

\subsection{Polymer Processing: Analysis of the Morphology}

Figure 1 reports the comparison between the as-spun mat (a) and a mat obtained after the spinning process and thermal treatment at $180^{\circ} \mathrm{C}(\mathrm{b})$. The SEM examination confirmed that the fibrous morphology displayed by the as-spun sample (average fiber diameter of $2.9 \pm 0.7 \mu \mathrm{m}$ ) was retained after the curing process (average fiber diameter of $2.8 \pm 0.8 \mu \mathrm{m}$ ).

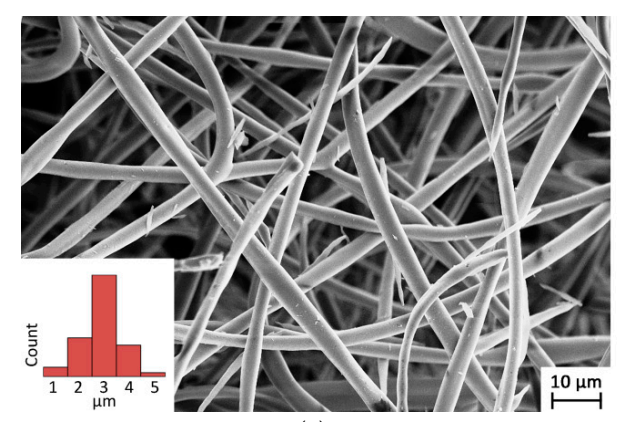

(a)

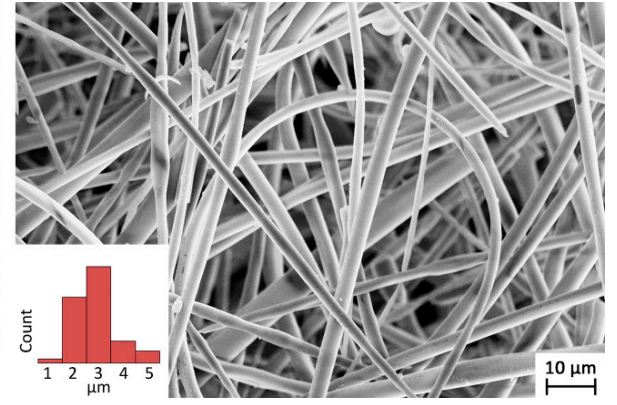

(b)

Figure 1. Scanning electron microscopy (SEM) image and fiber diameter distribution of the (a) as-spun polymer, and (b) thermal-treated sample. 


\subsection{DEET Loading Capacity Assessment}

Subsequently to the DEET loading process, the absorbed repellent was extracted in $8 \mathrm{~mL}$ of a methanol/water $(57 / 43 \mathrm{vol} / \mathrm{vol})$ mixture, and the total amount was estimated via HPLC/UV-Vis. Four consecutive extractions ( $1 \mathrm{~mL}$ each) of the same sample resulted in enough to assess a loading capacity of $130 \mathrm{mg} / \mathrm{g}$.

The loading capacity obtained for this system represents an interesting result, particularly when compared to the results reported in the study by Peila et al. (2017) [21], in which the best-performing system, a polyester incorporated with $\beta C D$, was characterized by a DEET loading capacity of $29 \mathrm{mg} / \mathrm{g}$.

\subsection{Thermogravimetric Analysis}

Additionally, a TGA of the loaded mat was performed and is reported in Figure 2a (solid line). Two different weight-loss phenomena were observed. The first, occurring approximately between 100 and $180{ }^{\circ} \mathrm{C}$, with a weight-loss rate maximum of close to $160{ }^{\circ} \mathrm{C}$ represented repellent volatilization from the matrix. The second, occurring above $200{ }^{\circ} \mathrm{C}$, was related to the thermal degradation of the nanosponges. The amount of DEET loaded into the fibers was then estimated through the weight loss observed between 100 and $180^{\circ} \mathrm{C}$. Following this approach, the loading capacity of the system was $173 \mathrm{mg} / \mathrm{g}$, thus being higher than that obtained via HPLC/UV-Vis. However, the thermogram showed that the weight-loss phenomena related to the DEET volatilization and to the nanosponge pyrolysis respectively were not well separated, as the end of the first overlapped the early stages of the second (Figure 2a, solid line). This overlap may have resulted in an overestimation of the system loading capacity calculated via the gravimetric approach.

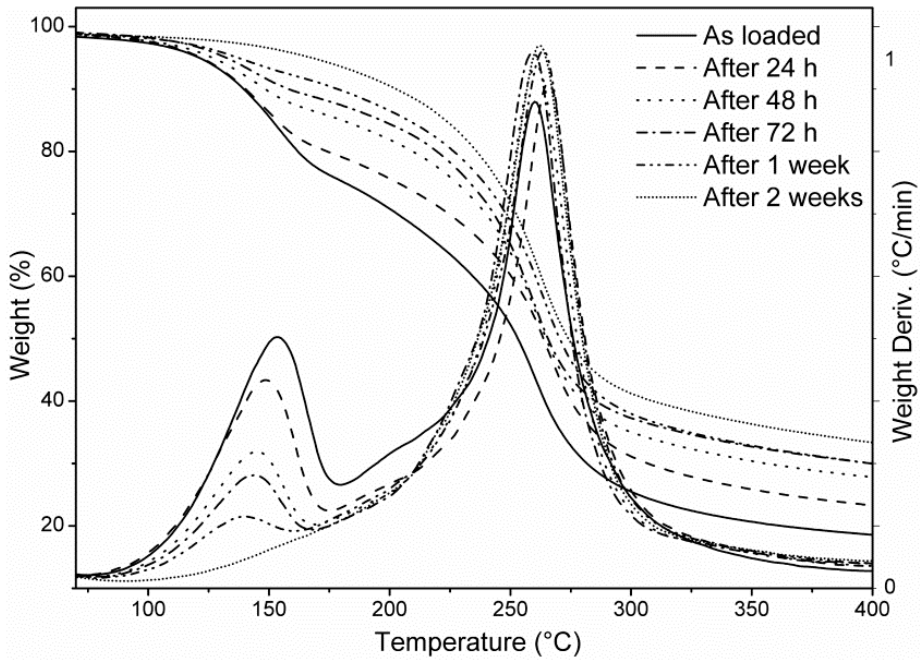

(a)

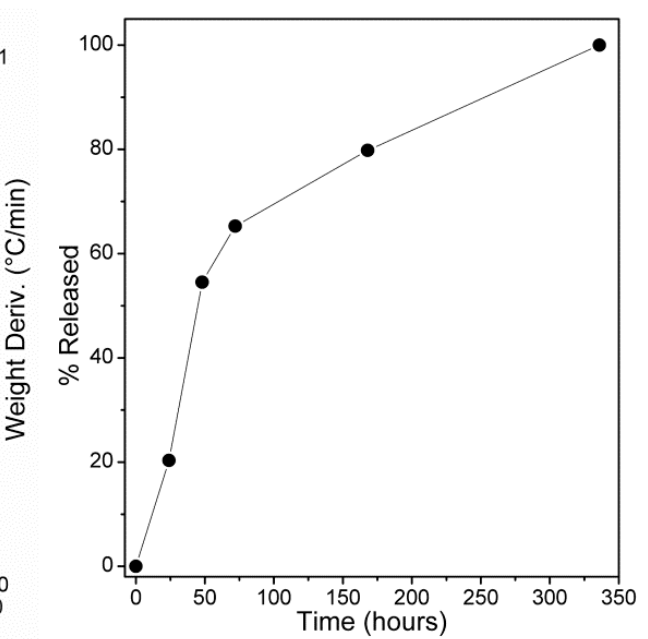

(b)

Figure 2. (a) Thermogravimetric analysis (TGA) of the as-loaded polymer $24 \mathrm{~h}, 48 \mathrm{~h}, 72 \mathrm{~h}, 1$ week, and 2 weeks after the loading step, respectively. (b) DEET releasing profile.

\subsection{DEET Release Study}

The overlap of the thermograms along with their respective derivative curves, resulting from the release study of DEET from the loaded matrix, are reported in Figure 2a. The comparison shows that the amount of loaded DEET decreased over time, indicating that the repellent gradually volatilized from the matrix. This decrease was more apparent in the derivatives' overlap, in which the intensity of the peak related to the DEET volatilization decreased by increasing the time the sample was left in open air. After 2 weeks of exposure, the weight loss related to DEET volatilization became negligible, indicating little or no residual DEET still loaded in the matrix. By assuming the 2 weeks $\left(t_{2}\right.$ weeks $)$ old 
sample as the $100 \%$ DEET-released scenario and the as-loaded $\left(t_{0}\right)$ sample as the $0 \%$ DEET-released scenario, the fraction of DEET released after each time interval $\left(t_{x}\right)$ was estimated as follows and is reported in Figure 2b:

$$
\text { DEET wt \% released at } t_{x}=\frac{\left(W t_{x}-W t_{0}\right)}{\left(W t_{2} \text { weeks }-W t_{0}\right)} * 100
$$

where $W t_{x}$ is the loaded DEET after each time interval $t_{x}, W t_{0}$ is the loaded DEET after the loading step (0\% DEET-released scenario), and $W t_{2}$ weeks is the $100 \%$ DEET-released scenario.

The release profile (Figure $2 \mathrm{~b}$ ) showed a rapid release over the first $72 \mathrm{~h}$, which consisted of more than $60 \%$ of the loaded DEET, followed by a slow release of the remaining amount over the next 11 days.

Host-guest complexes between $\beta C D$ and a large number of chemicals have been studied in the past decades [22]. Recently, it has been demonstrated how cyclodextrins appear to affect DEET formulation by complexation and emulsion stabilization, without negatively affecting its volatility [23]. Furthermore, tests carried out on $\beta C D$-grafted fabrics have already been reported [15,21]. Thus, considering the polymer chemical composition and its molecular arrangement, two types of molecular interactions between the sample and the DEET molecules could be hypothesized: one consisting of host-guest inclusion complexes expressed by the $\beta C D$ molecules composing the polymer; additionally, another interaction expressed by the sterical entrapment of the repellent within the cross-linked polymer chains. The two different interactions could explain the release profile. The first release, occurring during the first $72 \mathrm{~h}$, may have been due to the molecules entrapped within the polymer network, which were less retained and thus free to volatilize rapidly. Vice versa, the complexed DEET molecules could justify the slower release that occurred over the remaining 11 days, which consisted of less than $40 \%$ of the total amount.

Nevertheless, as it is possible to observe from Figure 3, the releasing profile could also be easily fitted with a logarithm curve. Given this result, the volatilization of DEET from the matrix could also be described by the following equation:

$$
d\left[Q_{D E E T}\right] / d t=k\left[Q_{D E E T}\right]
$$

in which the volatilization rate was dependent only on the quantity of loaded DEET ([ $\left.\left.Q_{D E E T}\right]\right)$.

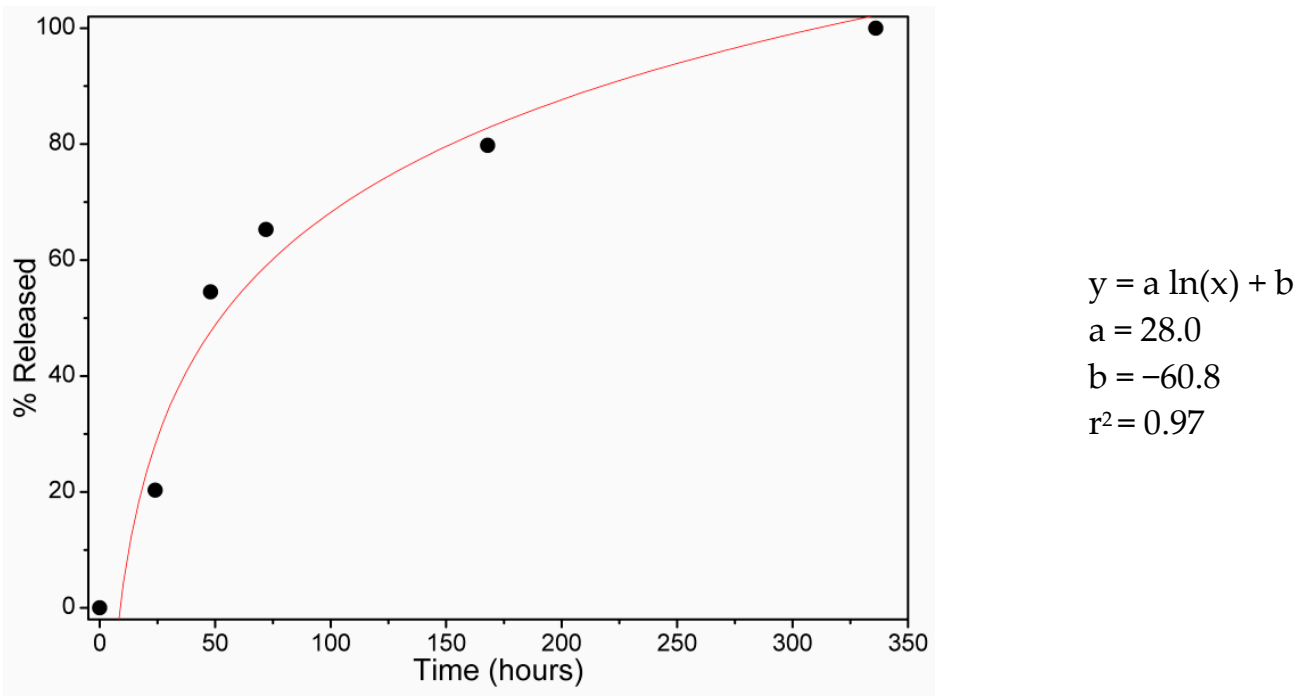

Figure 3. Logarithm fit of DEET releasing profile. 


\subsection{DEET Loading Capacity with Respect to the Morphology and Chemical Composition}

The thermograms reported in Figure 4 show how the chemical nature of the $\beta C D$-based polymer deeply affected its capability to load guest molecules, when compared to a standard fabric-like cotton, which showed an almost negligible loading. A higher loading capacity, approximately 4 times higher than that of the cotton fabric, was displayed by the cotton swab. This result was likely due to its less compact structure compared to the cotton fabric. However, the loading capacity displayed by the cotton swab was still lower when compared to that of the $\beta C D$ polymer sample. Moreover, given the absence of strong intermolecular interactions with this kind of sample, a fast DEET release due to volatilization was also expected.

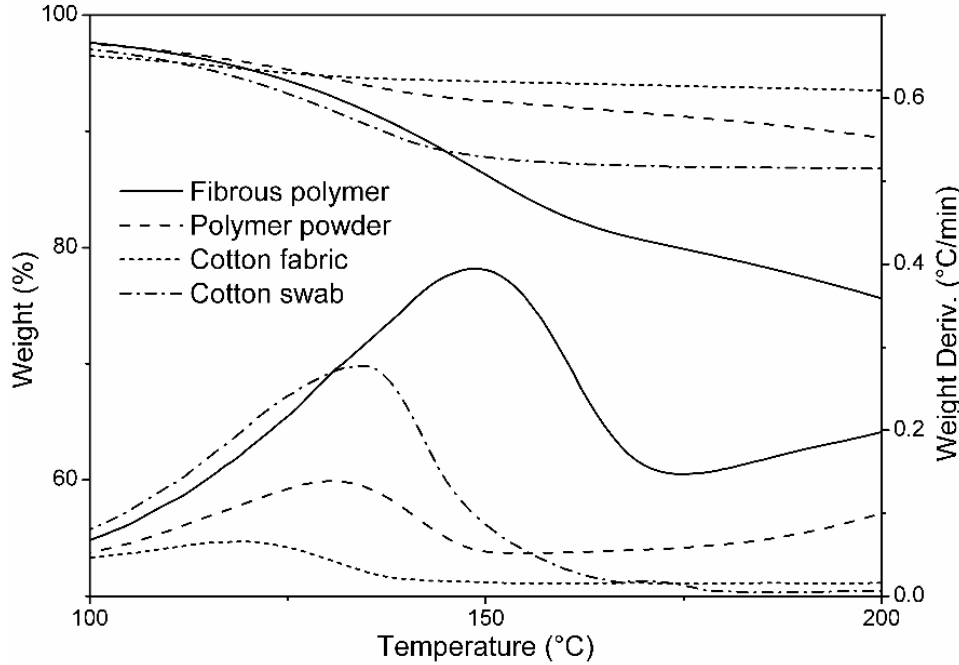

(a)

\begin{tabular}{cc}
\hline Sample & $\begin{array}{c}\text { Loading } \\
\text { Capacity } \\
\text { (mg/g) }\end{array}$ \\
\hline Fibrous polymer & 173 \\
Polymer powder & 65 \\
Cotton fabric & 27 \\
Cotton swab & 102 \\
\hline
\end{tabular}

(b)

Figure 4. (a) Thermogravimetric analysis (TGA) and (b) DEET loading capacity of beta-cyclodextrin $(\beta C D)$-based fibrous polymer (Fibrous polymer), the same polymer but with powder morphology (Polymer powder), a pure cotton fabric (Cotton fabric), and a cotton swab (Cotton swab).

The comparison between the TGA of both $\beta C D$-based polymers (Figure 3 ) demonstrated that the fibrous morphology played a key role in increasing the loading capacity. This observation reflects the results reported in the work of Peila et al. (2017) [21]. In that work, $\beta C D$-based powder samples (comparable to the polymer powder reported in this work) were loaded with DEET and then incorporated into polyester fabrics. The loading capacity observed resulted in the same magnitude of the polymer powder.

It was also apparent that, for the fibrous polymer, the weight-loss rate maximum (associated to DEET volatilization) was shifted towards higher temperatures with respect to both the polymer powder and cotton samples. This behavior could be related to the capability of the fibrous $\beta C D$-based polymer to create stronger interactions with DEET molecules.

A high surface-to-volume ratio typical of the fibrous samples (absent in the polymer powder) and a chemical structure capable to accommodate guest molecules, typical of $\beta C D$-based products (absent in standard fabrics), were both present in this system and were demonstrated to deeply affect the system performance.

\section{Conclusions}

A water-soluble $\beta C D$-based polymer was obtained using PMDA as a linking molecule and working under critical dilution conditions. Because of the polymer solubility features, an electrospinning technique was used to produce fibrous mats, using distilled water as the unique solvent, while a subsequent one-step thermal treatment (of the spun mat) allowed fibrous $\beta C D$-based 
nanosponges to be obtained. The final sample morphology was characterized by well-defined fibers with a fiber diameter distribution of $2.8 \pm 0.8 \mu \mathrm{m}$.

Because $\beta C D$-based nanosponges are known as a powerful tool for the controlled release of drugs and chemicals, the loading capacity and the controlled release of the obtained fibrous nanosponges towards a common insect repellent (DEET) were studied.

HPLC/UV-Vis was used to assess the DEET loading capacity, which was found to be $130 \mathrm{mg} / \mathrm{g}$, while the release of the repellent from the matrix was followed via gravimetric analysis and lasted for over 2 weeks. From the releasing profile, it was possible to hypothesize two loading mechanisms consisting of host-guest complexes and steric entrapment, and as a result of the successful logarithm fit of the releasing profile, it was also possible to demonstrate how the volatilization of DEET from the matrix was dependent on the loaded DEET amount.

Comparisons with a cotton fabric and a cotton swab, loaded following the same procedure as for the $\beta C D$-based nanosponges, demonstrated how the chemical composition of the $\beta C D$-based nanosponges was an essential feature in order to reach high loading capacities. Eventually, it was proven how the sample morphology also affected the high DEET loading capacity of the system, by comparing the spun polymer with the same polymer matrix but in powder form, loaded the same way as for the fibrous mat.

The results obtained can be considered an encouraging starting point for further works, as the system fully demonstrated the capability to host DEET molecules and provide a gradual release over time.

Author Contributions: Methodology, C.C. and F.C.; Investigation, C.C. and F.C.; Writing-Original Draft Preparation, C.C.; Writing—Review \& Editing, C.C., P.B., M.Z. and F.T.; Supervision, F.T.; Project Administration, P.B. and M.Z.

Funding: APC was sponsored by MDPI.

Conflicts of Interest: The authors declare no conflict of interest.

\section{References}

1. Mayer, S.V.; Tesh, R.B.; Vasilakis, N. The emergence of arthropod-borne viral diseases: A global prospective on dengue, chikungunya and zika fevers. Acta Trop. 2017, 166, 155-163. [CrossRef] [PubMed]

2. Blitvich, B. Arboviruses: Molecular Biology, Evolution and Control. Nikos Vasilakis and Duane J. Gubler. Am. J. Trop. Med. Hyg. 2016, 95, 488-489. [CrossRef] [PubMed]

3. Diaz, J.H. Chemical and plant-based insect repellents: Efficacy, safety, and toxicity. Wilderness Environ. Med. 2016, 27, 153-163. [CrossRef] [PubMed]

4. Alpern, J.D.; Dunlop, S.J.; Dolan, B.J.; Stauffer, W.M.; Boulware, D.R. Personal Protection Measures Against Mosquitoes, Ticks, and Other Arthropods. Med. Clin. N. Am. 2016, 100, 303-316. [CrossRef] [PubMed]

5. Tavares, M.; da Silva, M.R.M.; de Oliveira de Siqueira, L.B.; Rodrigues, R.A.S.; Bodjolle-d'Almeira, L.; dos Santos, E.P.; Ricci-Júnior, E. Trends in insect repellent formulations: A review. Int. J. Pharm. 2018, 539, 190-209. [CrossRef] [PubMed]

6. Barradas, T.N.; Lopes, L.M.A.; Ricci, E.; De Holanda E Silva, K.G.; Mansur, C.R.E. Development and characterization of micellar systems for application as insect repellents. Int. J. Pharm. 2013, 454, 633-640. [CrossRef] [PubMed]

7. Islam, J.; Zaman, K.; Duarah, S.; Raju, P.S.; Chattopadhyay, P. Mosquito repellents: An insight into the chronological perspectives and novel discoveries. Acta Trop. 2017, 167, 216-230. [CrossRef] [PubMed]

8. Yoon, J.K.; Kim, K.C.; Cho, Y.; Gwon, Y.D.; Cho, H.S.; Heo, Y.; Park, K.; Lee, Y.W.; Kim, M.; Oh, Y.K.; et al. Comparison of Repellency Effect of Mosquito Repellents for DEET, Citronella, and Fennel Oil. J. Parasitol. Res. 2015, 2015. [CrossRef] [PubMed]

9. Antwi, F.B.; Shama, L.M.; Peterson, R.K.D. Risk assessments for the insect repellents DEET and picaridin. Regul. Toxicol. Pharmacol. 2008, 51,31-36. [CrossRef] [PubMed]

10. Caldera, F.; Tannous, M.; Cavalli, R.; Zanetti, M.; Trotta, F. Evolution of Cyclodextrin Nanosponges. Int. J. Pharm. 2017. [CrossRef] [PubMed] 
11. Trotta, F. Cyclodextrins in Pharmaceutics, Cosmetics, and Biomedicine: Current and Future Industrial Applications. Cyclodext. Pharm. Cosmet. Biomed. Curr. Futur. Ind. Appl. 2011, 17, 323-342. [CrossRef]

12. Davis, M.E.; Brewster, M.E. Cyclodextrin-based pharmaceutics: Past, present and future. Nat. Rev. Drug Discov. 2004, 3, 1023-1035. [CrossRef] [PubMed]

13. Trotta, F.; Zanetti, M.; Cavalli, R. Cyclodextrin-based nanosponges as drug carriers. Beilstein J. Org. Chem. 2012, 8, 2091-2099. [CrossRef] [PubMed]

14. Swaminathan, S.; Cavalli, R.; Trotta, F. Cyclodextrin-based nanosponges: A versatile platform for cancer nanotherapeutics development. Wiley Interdiscip. 2016, 8, 579-601. [CrossRef] [PubMed]

15. Romi, R.; Nostro, P.L.; Bocci, E.; Ridi, F.; Baglioni, P. Bioengineering of a Cellulosic Fabric for Insecticide Delivery via Grafted Cyclodextrin. Biotechnol. Prog. 2005, 21, 1724-1730. [CrossRef] [PubMed]

16. Li, D.; Xia, Y. Electrospinning of nanofibers: Reinventing the wheel? Adv. Mater. 2004, 16, 1151-1170. [CrossRef]

17. Bhardwaj, N.; Kundu, S.C. Electrospinning: A fascinating fiber fabrication technique. Biotechnol. Adv. 2010, 28, 325-347. [CrossRef] [PubMed]

18. Pham, Q.P.; Sharma, U.; Mikos, A.G. Electrospinning of polymeric nanofibers for tissue engineering applications: A review. Tissue Eng. 2006, 12, 1197-1211. [CrossRef] [PubMed]

19. Cecone, C.; Caldera, F.; Anceschi, A.; Scalarone, D.; Trotta, F.; Bracco, P.; Zanetti, M. One-step facile process to obtain insoluble polysaccharides fibrous mats from electrospinning of water-soluble PMDA/cyclodextrin polymer. J. Appl. Polym. Sci. 2018, 135, 46490. [CrossRef]

20. Trotta, F.; Caldera, F.; Cavalli, R.; Mele, A.; Punta, C.; Melone, L.; Castiglione, F.; Rossi, B.; Ferro, M.; Crupi, V.; et al. Synthesis and characterization of a hyper-branched water-soluble $\beta$-cyclodextrin polymer. Beilstein J. Org. Chem. 2014, 10, 2586-2593. [CrossRef] [PubMed]

21. Peila, R.; Scordino, P.; Shanko, D.B.; Caldera, F.; Trotta, F.; Ferri, A. Synthesis and characterization of $\beta$-cyclodextrin nanosponges for $N, N$-diethyl-meta-toluamide complexation and their application on polyester fabrics. React. Funct. Polym. 2017, 119, 87-94. [CrossRef]

22. Saenger, B.W. Cyclodextrin Inclusion Compounds in Research and Industry. Angew. Chem. Int. Ed. Engl. 1980, 8, 344-362. [CrossRef]

23. Proniuk, S.; Liederer, B.M.; Dixon, S.E.; Rein, J.A.; Kallen, M.A.; Blanchard, J. Topical Formulation Studies with DEET (N,N-Diethyl-3-methylbenzamide) and Cyclodextrins. J. Pharm. Sci. 2002, 91, 101-110. [CrossRef] [PubMed]

Sample Availability: Samples of the compounds are available from the authors.

(C) 2018 by the authors. Licensee MDPI, Basel, Switzerland. This article is an open access article distributed under the terms and conditions of the Creative Commons Attribution (CC BY) license (http://creativecommons.org/licenses/by/4.0/). 